\title{
1-S03-4 Symposium
}

\section{$\mathrm{Ca}^{2+}$-activated $\mathrm{K}^{+}$channel as potential therapeutic target for cancer treatment}

\section{Susumu Ohya $^{1}$}

${ }^{\text {I} D e p t . P h a r m a c o l ., ~ G r a d . ~ S c h . ~ M e d . ~ S c i ., ~ N a g o y a ~ C i t y ~ U n i v . ~}$

In cancer cells, $\mathrm{Ca}^{2+}$-activated $\mathrm{K}^{+}$channels $\mathrm{K}_{\mathrm{Ca}} 1.1$ and $\mathrm{K}_{\mathrm{Ca}} 3.1$ are co-localized with $\mathrm{Ca}^{2+}$-permeable Orai/TRP channels to provide a positive-feedback loop for $\mathrm{Ca}^{2+}$ entry. They are responsible for the promotion of cell growth and metastasis in the different types of cancer, and are therefore potential therapeutic targets and biomarkers for cancer. We determined the epigenetic and post-transcriptional dysregulation of $\mathrm{K}_{\mathrm{Ca}} 3.1$ by class I histone deacetylase (HDAC) inhibitors in breast and prostate cancer cells. We further determined the transcriptional repression and protein degradation of $\mathrm{K}_{\mathrm{Ca}} 1.1$ by vitamin $\mathrm{D}$ receptor (VDR) agonists and androgen receptor (AR) antagonists, which are expected as potential therapeutic drugs for triple-negative breast cancer. A class III HDAC, SIRT1 is involved in cancer growth, stemness, and metastasis. We here introduce SIRT1-mediated regulation of $\mathrm{K}_{\mathrm{Ca}} 3.1$ expression in breast, prostate, and colorectal cancer by three-dimensional spheroid culture. The anti-inflammatory cytokine, interleukin-10 (IL-10) is an immunosuppressive factor involved in tumorigenesis, and plays a crucial role in escape from tumor immune surveillance. We determined $\mathrm{K}_{\mathrm{Ca}} 3.1$ activators are a possible therapeutic option to suppress the tumor-promoting activities of IL-10. These results may provide new insights into cancer treatment focused on $\mathrm{Ca}^{2+}$ activated $\mathrm{K}^{+}$channels. 